\title{
Questionnaires to evaluate pelvic floor dysfunction in the postpartum period: a systematic review
}

This article was published in the following Dove Press journal: International Journal of Women's Health

\author{
Lea Tami Suzuki Zuchelo1,2 \\ Italla Maria Pinheiro \\ Bezerral,3 \\ Adna Thaysa Marcial Da \\ Silva ${ }^{1,4}$ \\ Jéssica Menezes Gomes 1,4 \\ José Maria Soares Júnior ${ }^{4}$ \\ Edmund Chada Baracat ${ }^{4}$ \\ Luiz Carlos de Abreu ${ }^{1,3}$ \\ Isabel Cristina Esposito \\ Sorpreso ${ }^{1,4}$ \\ 'Study Design and Scientific Writing \\ Laboratory at ABC Medical School, \\ Santo André, Brazil; ${ }^{2}$ Research \\ Laboratory of Uninorte (Barão do Rio \\ Branco Faculty), Rio Branco, Brazil; \\ ${ }^{3}$ School of Sciences of Santa Casa de \\ Misericórdia de Vitoria, Vitória, Brazil; \\ ${ }^{4}$ Faculty of Medicine, University of São \\ Paulo, São Paulo, Brazil
}

Correspondence: Isabel Cristina Esposito Sorpreso

Faculty of Medicine, University of São Paulo, Enéas de Carvalho Aguiar Avenue, $\mathrm{n} 255,10^{\circ}$ Floor, Room 10166, Zipcode 05403-000, São Paulo,

São Paulo, Brazil

Tel +55 | | 266 | 762 I

Email icesorpreso@usp.br
Background: Pelvic floor dysfunctions (PFDs) affect the female population, and the postpartum period can be related to the onset or aggravation of the disease. Early identification of the symptoms and the impact on quality of life can be achieved through assessment instruments.

Objective: The purpose of this systematic review is to evaluate questionnaires used to assess PFD in the postpartum period.

Methods: A systematic review study was conducted, following Preferred Reporting Items for the Systematic Reviews and Meta-Analyses (PRISMA) criteria, using the databases: PubMed, Biblioteca Virtual de Saúde (BVS), Web of Science, and Scopus, and the keywords PFD or pelvic floor disorders, postpartum or puerperium, and questionnaire. Articles published up till May 2018 were included, searching for articles using validated questionnaires for the evaluation of PFDs in postpartum women. The articles included were evaluated according to a checklist, and the validation studies and translated versions of the questionnaires were identified.

Results: The search of the databases resulted in 359 papers, and 33 were selected to compose this systematic review, using nine validated questionnaires to assess PFDs in the postpartum period: International Consultation on Incontinence Questionnaire - Vaginal Symptoms (ICIQ-VS), Pelvic Floor Distress Inventory 20 (PFDI-20), Pelvic Floor Impact Questionnaire (PFIQ-7), PFDI-46, Pelvic Floor Impact Questionnaire (PFIQ-31), Pelvic Floor Bother Questionnaire (PFBQ), Female Pelvic Floor Questionnaire, electronic Personal Assessment Questionnaire - Pelvic Floor, and PFD questionnaire specific for pregnancy and postpartum. The most frequently reported questionnaires included PFDI-20, PFIQ-7, and ICIQ-VS and are recommended by ICI. In addition, the review identified a specific questionnaire, recently developed, to access PFD during pregnancy and postpartum. Conclusion: The questionnaires used to evaluate PFD during postpartum period are developed for general population or urology/gynecology patients with incontinence and reinforce the paucity of highly recommended questionnaires designed for postpartum, in order to improve early and specific approach for this period of life.

Keywords: pelvic floor disorders, puerperium, women's health, primary health care, surveys and questionnaires, patient reported outcome measure

\section{Background}

Pelvic floor dysfunctions (PFDs) comprise a wide variety of interrelated clinical conditions, such as urinary incontinence (UI), fecal incontinence (FI), pelvic organ prolapse (POP), sexual dysfunction, and other urogenital symptoms They affect $23 \%-49 \%$ of women in general, ${ }^{1,2}$ with an increasing incidence estimate to 43.8 million cases in 2050 in developed and developing countries, ${ }^{3,4}$ resulting in negative repercussions (emotional and physical) on women's quality of life (QoL).

The development of PFDs is a complex process secondary to multifactorial etiology. The pregnancy-puerperal cycle is one of the periods correlated with 
the onset or aggravation of the disorders. ${ }^{5}$ The postpartum period provides a window of opportunity for early identification of symptoms to provide health promotion actions, thus reducing the development of PFDs and their consequences.

The precocious perception of these symptoms in puerperium depends on factors such as access and quality of care from the health team, as urogenital symptoms are accepted by women as a natural consequence of childbirth and/or aging, which may delay the diagnosis and treatment of PFDs. ${ }^{6}$

The questionnaires are health instruments that aid in fleshing out the proper analysis of the patient. ${ }^{7}$ They are used to assess PFDs that identify urogenital symptoms, quantify the intensity and severity of symptoms, assess the impact on women's QoL, and are used as a clinical parameter in the treatment and evolution of PFDs. Moreover, in medical research, they are not invasive features and are low in cost, facilitating the reproducibility of the method. ${ }^{8,9}$

Thus, the objective of this systematic review is to evaluate questionnaires used to assess PFD in the postpartum period.

\section{Methods}

A systematic review of articles was conducted according to the Preferred Reporting Items for the Systematic Reviews and Meta-Analyses (PRISMA) Statement. ${ }^{10}$

\section{Search strategy}

Articles published until May 2018 were included, and the search was limited to articles published in peer-reviewed journals, using questionnaires for the evaluation of PFDs in postpartum women.

A systematic literature search of studies without limits on the publication date was conducted in the PubMed databases (https://www.ncbi.nlm.nih.gov/pubmed), Virtual Health Library (http://bvsalud.org), Web of Science (https://isiknowledge.com), and Scopus (https://www. scopus.com). The terms used for the search were pelvic floor dysfunction OR pelvic floor disorders; AND postpartum OR puerperium; AND questionnaire. These keywords were selected according to the Medical Subject Headings (MeSH) in the National Library of Medicine and also by their synonyms.

Selection of the keywords for searching the databases followed the PICOS model. The Population (P) was defined as women in the postpartum period with no time limit; the Intervention (I) must be the use of questionnaire to evaluate PFD; the Outcome $(\mathrm{O})$ was the results of PFD's questionnaires; the Comparison group (C) was not applicable; the Study (S) design excluded were data-based articles (eg, review articles, guidelines, books).

\section{Selection strategy}

Initially, the duplicated articles were excluded, and then we undertook a screening of titles and abstracts according to the following exclusion criteria: 1) were not published in English, Portuguese, or Spanish languages; 2) were not related to the issue; 3) were not available for free access.

After this step, the remaining articles were read in full text and evaluated according to the following inclusion criteria: 1) in the method section the use of a validated questionnaire, in any female population, to evaluate the PFD must be described. 2) There was no restriction on sample size or study design (eg, cohort study, case-control, randomized clinical trial, cross-sectional studies), except to data-based articles (eg, reviews, guidelines, books).

The articles were excluded if they 1) used only specific questionnaires for urinary incontinence, FI, sexual dysfunctions, QoL in general or pain; 2) used adaptations or modifications of validated questionnaires (Figure 1).

To improve confidence in the selection of articles, the abstracts and full-text evaluation was conducted by two researchers in an independent and blinded way, strictly following the inclusion and exclusion criteria. In cases where there was disagreement over the selection of studies among the investigators, a third reviewer was consulted.

\section{Strategy for analyzing selected articles}

By the criteria described above, the articles were selected to compose this systematic review. The articles included in the review were evaluated according to a checklist to identify the following information: the PFD questionnaires used in each article, subjects, postpartum period of the assessment, other evaluation techniques used in data collection, article goal, and conclusion.

The validation studies of the questionnaires were found in the references, and the translated versions were searched in all databases of the research (PubMed databases, Virtual Health Library, Web of Science, and Scopus) without limitation of languages or date.

\section{Results}

The search of the databases resulted in 359 papers. Screening by title and abstract, 169 were excluded as duplicated titles and 19 as irrelevant to study purposes. The remaining articles 


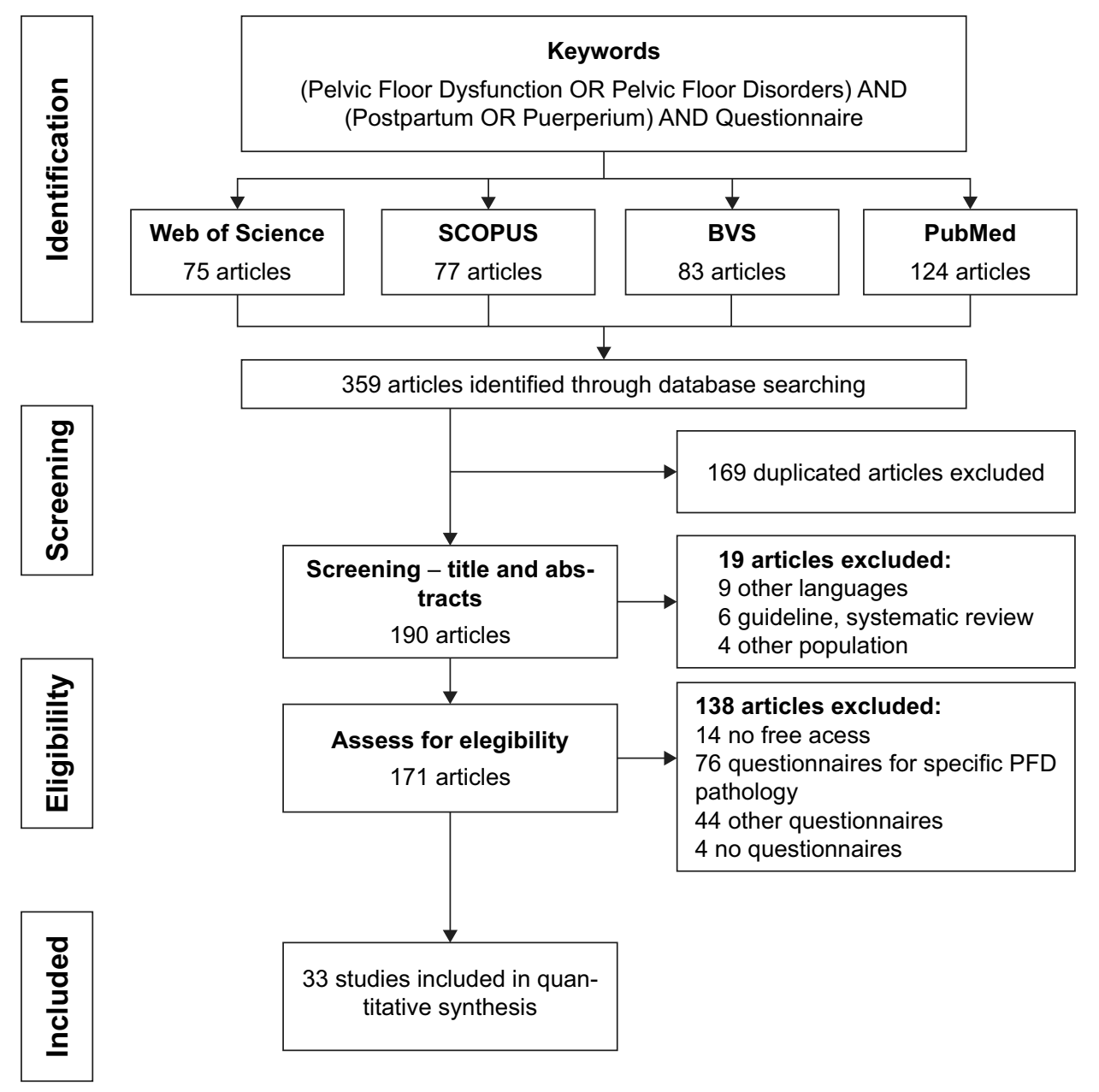

Figure I Systematic presentation of methodology use and selection criteria.

were read in their entirety, and 138 articles did not meet the inclusion criteria; thus, 33 articles were selected to compose this systematic review (Figure 1).

The 33 articles were published between 2007 and 2018, and the following information were included in Table 1: authors and year of publication, study design, population studied (n), questionnaires used, other techniques used in data collection, objective, and conclusion of the studies.

The instruments were applied in different periods of pregnancy and postpartum. One study initiated the follow-up before the pregnancy, ${ }^{12}$ and the postpartum period varied from 3 days $^{30,33}$ up to 5 years. ${ }^{19,38}$

The questionnaires were used in different types of studies, including cohort, ${ }^{12,14,17-21,23,25,27,31-33,35-40,43}$ cross-sectional, ${ }^{11,13 \text {, }}$ 16,24,26,29,34,41,42 pilot study, ${ }^{15}$ case-control, ${ }^{30}$ and randomized clinical trials. ${ }^{22,28}$

In total, we identified nine questionnaires used to assess PFDs in the postpartum period. The description of these questionnaires, frequency of use in the articles, and translated and validated versions for different languages are shown in Table 2.

The Pelvic Floor Distress Inventory-20 (PFDI-20) and the Pelvic Floor Impact Questionnaire-7 (PFIQ-7) ${ }^{44}$ are the two most frequent questionnaires in the articles included in this review, being used in $30.3 \%$ and $27.3 \%$ of studies, respectively. They assess urinary symptoms, POP, and colorectal symptoms and have versions translated into 17 and 16 different languages, respectively. ${ }^{44-60}$

The International Consultation on Incontinence Questionnaire - Vaginal Symptoms (ICIQ-VS) ${ }^{61}$ is the third most frequent questionnaire in this review, being used in $24.2 \%$ of the studies. It assesses vaginal symptoms, including POPs and sexual matters, and has versions translated into seven different languages. ${ }^{61-66}$ The Female Pelvic Floor Questionnaire (FPFQ) $)^{67,68}$ or Australian Questionnaire is the fourth most frequent in this review, being used in $12.1 \%$ of the studies. It assesses bladder, bowel, POP, and sexual domains, and has versions translated in three different languages. ${ }^{67-71}$ 


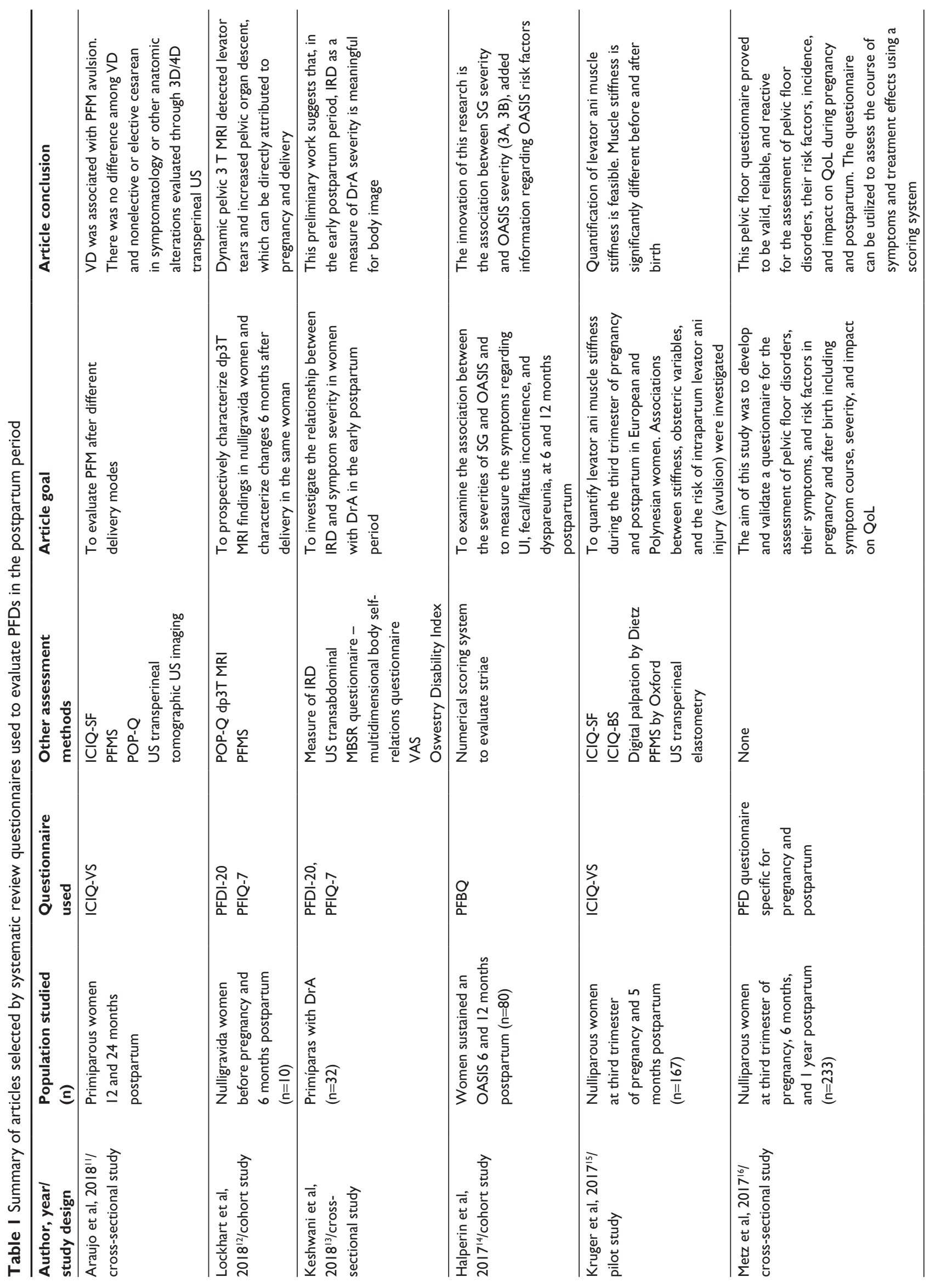




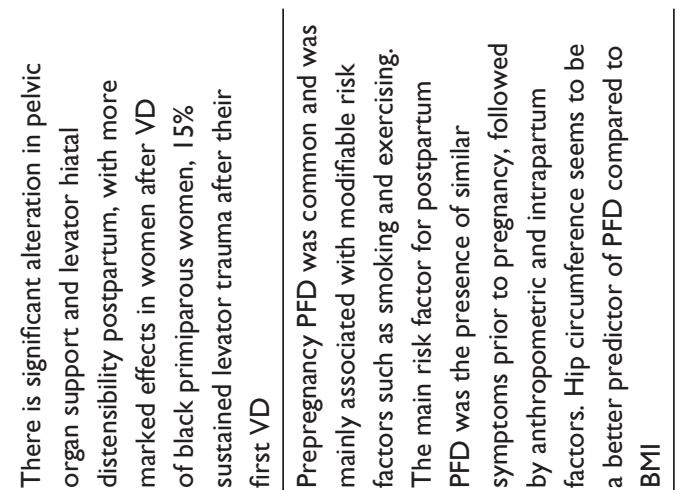

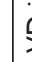

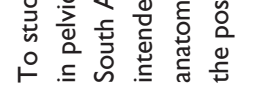

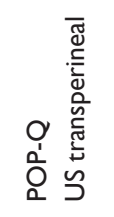

$\underline{\widetilde{d}}$
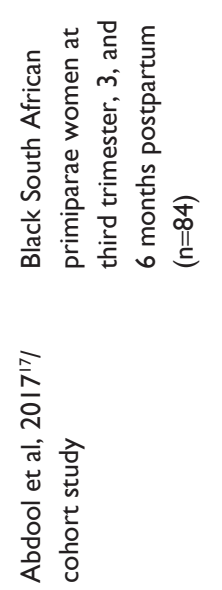
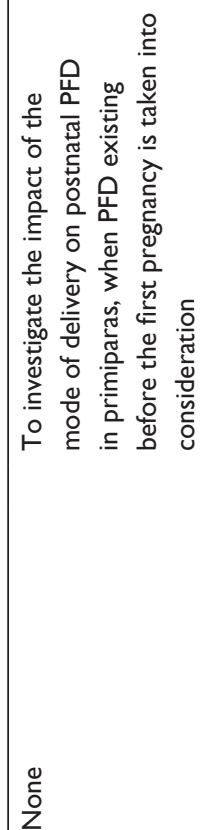

z

0
0
$\vdots$
0
0

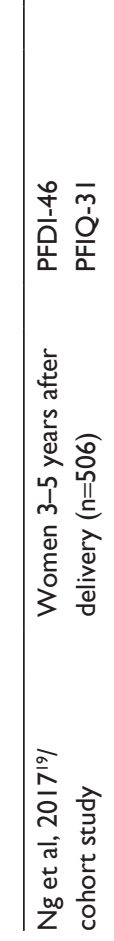

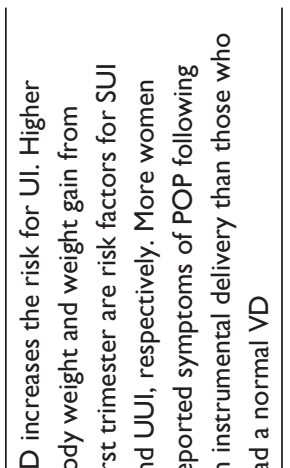

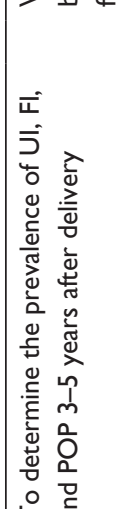

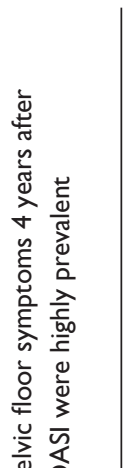

$\frac{\substack{2 \\ 0}}{2} \frac{1}{0}$

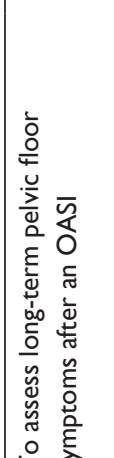

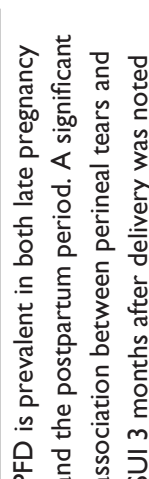

$$
\mid
$$

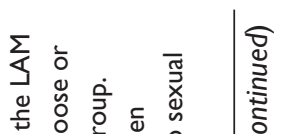

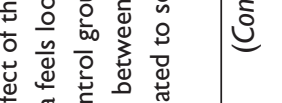

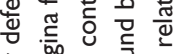

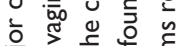
हैं

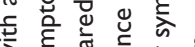
उ

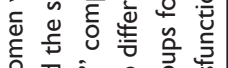

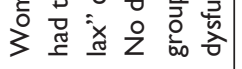

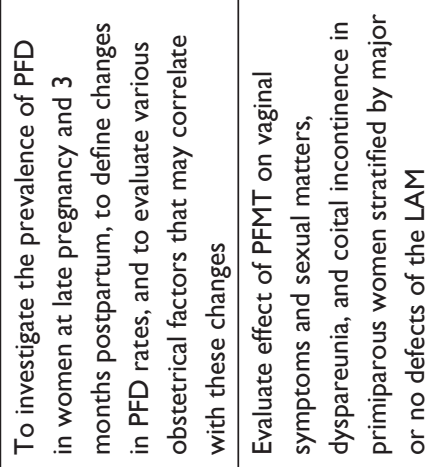

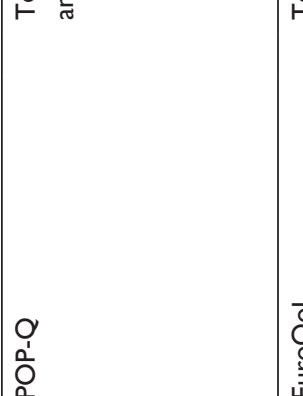

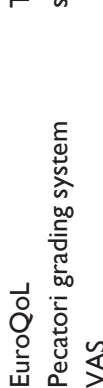
:

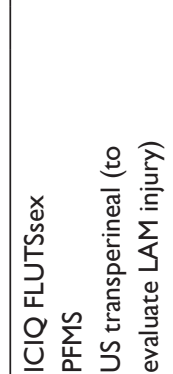
$\underline{\underline{u}}$

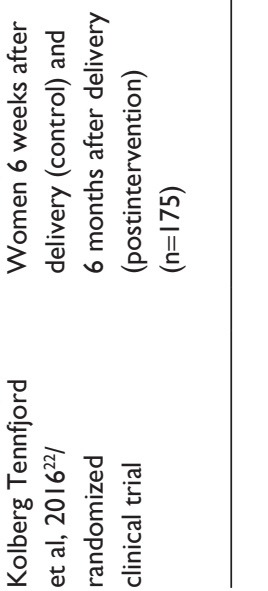




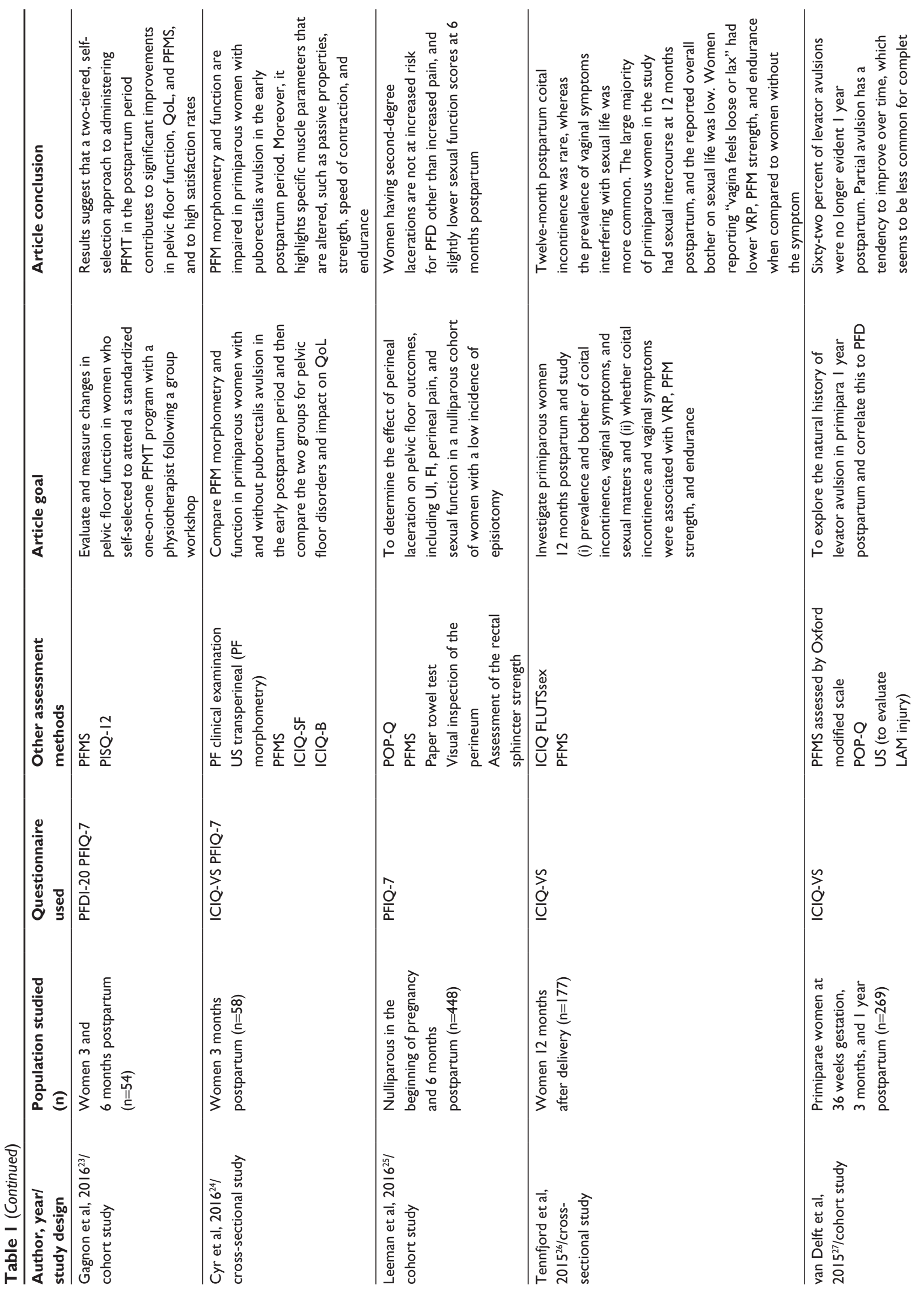




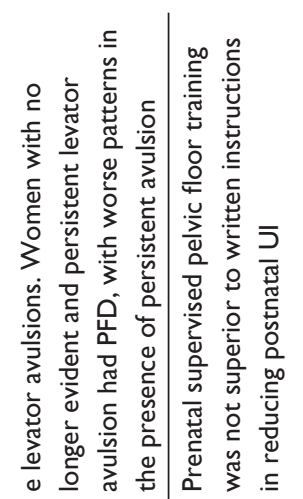

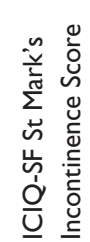
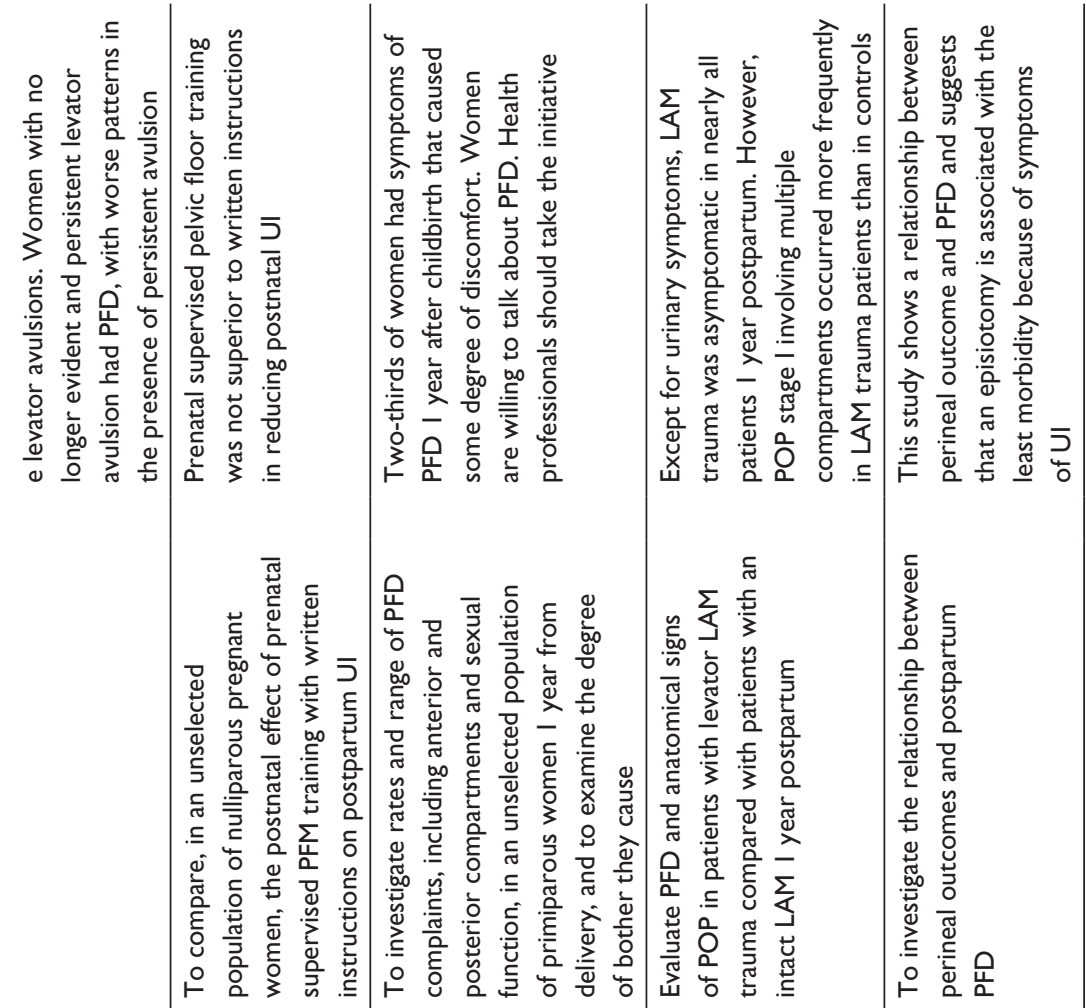

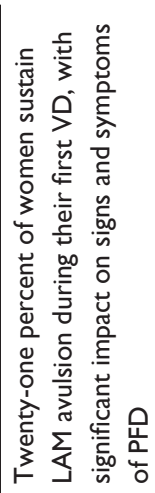
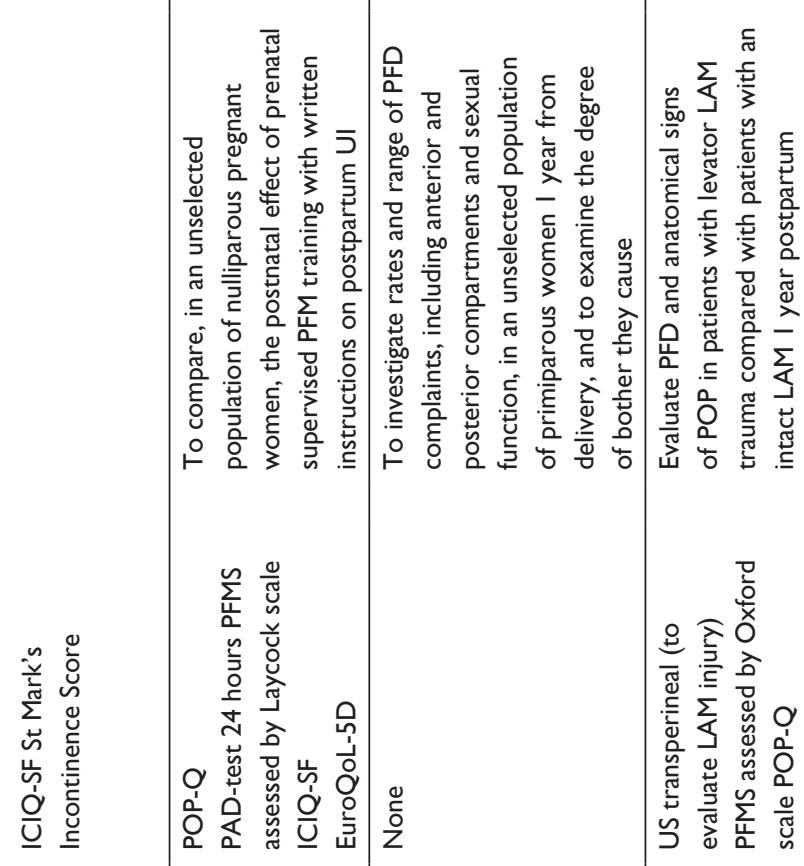

$$
\text { 일 }
$$

운

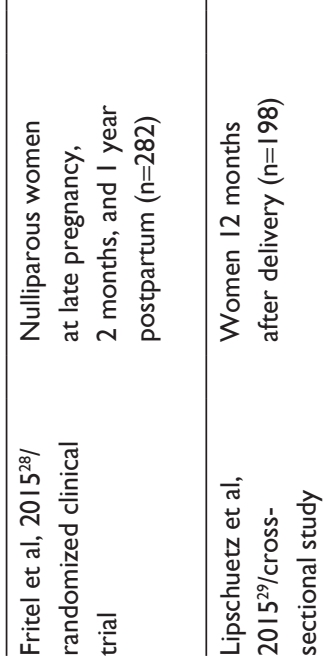

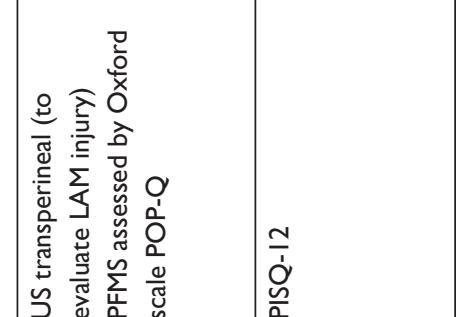

$\frac{1}{2}$ 음 음

옴 |

$\underline{\underline{U}}$

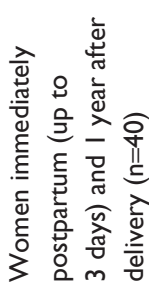

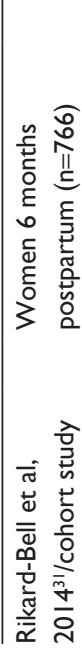

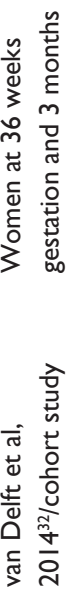

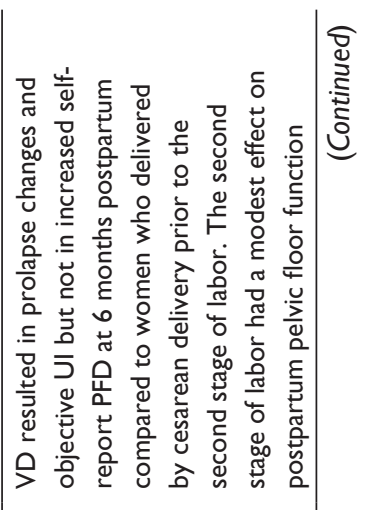

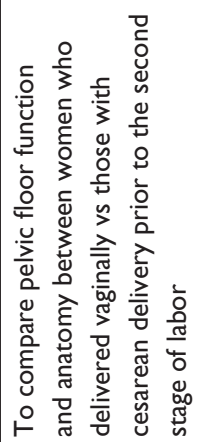

웜

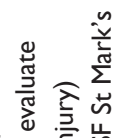

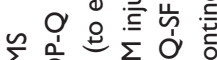

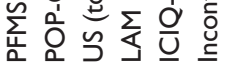

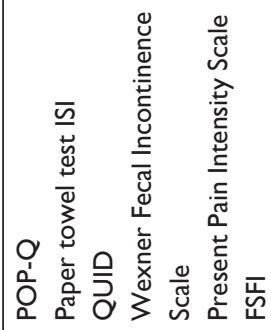

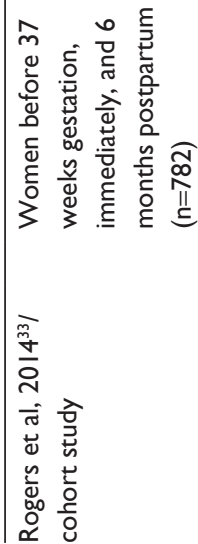




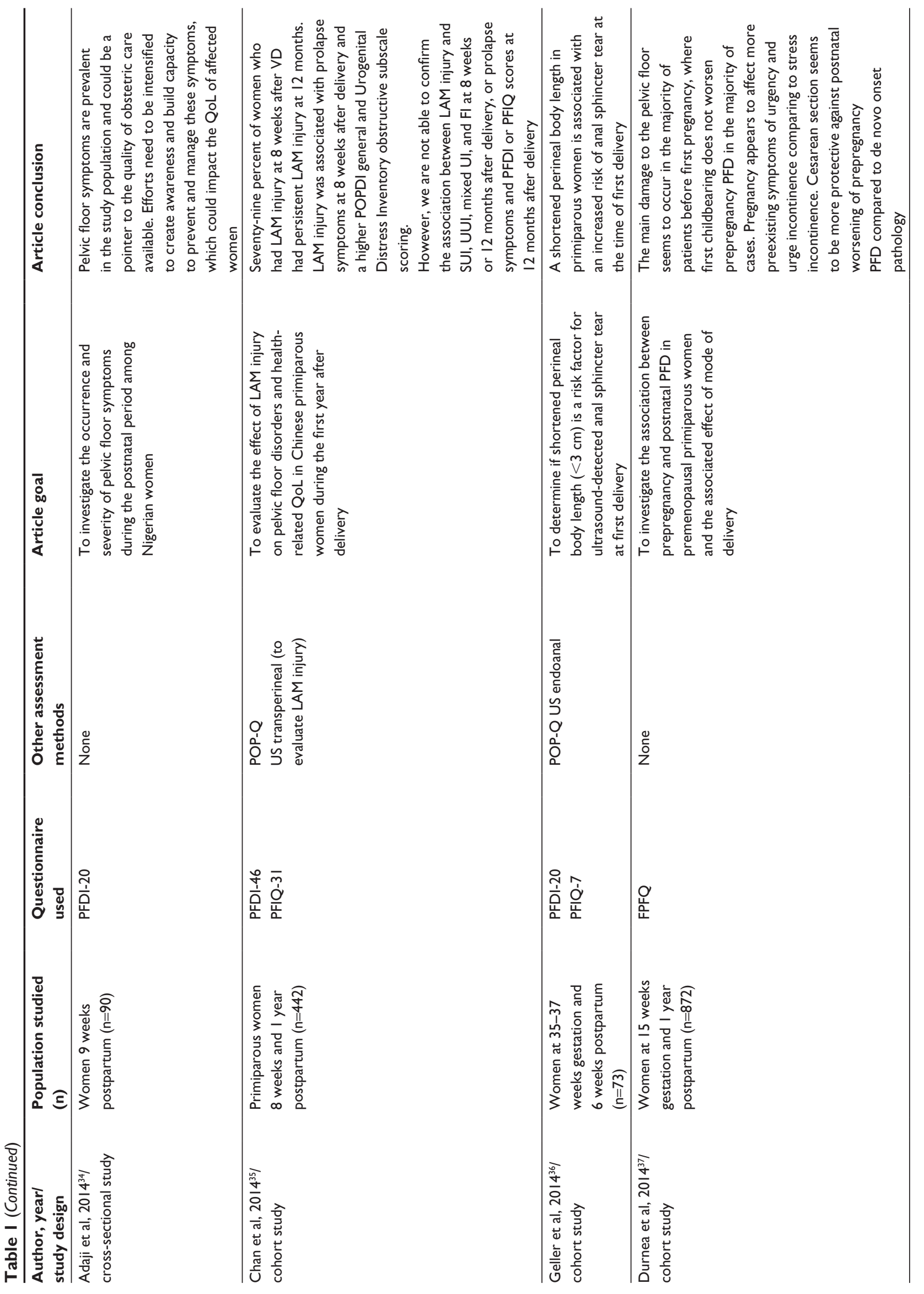




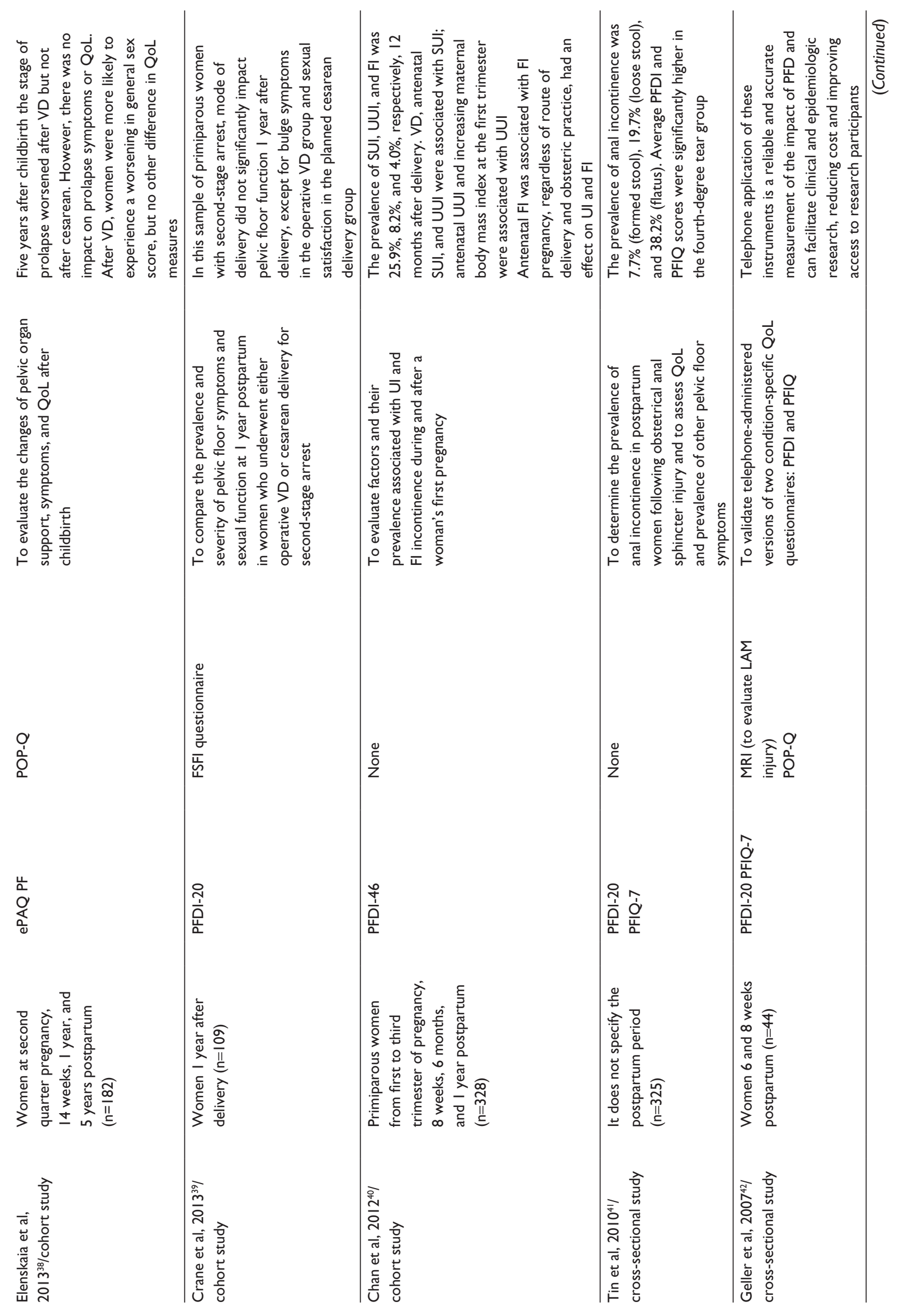




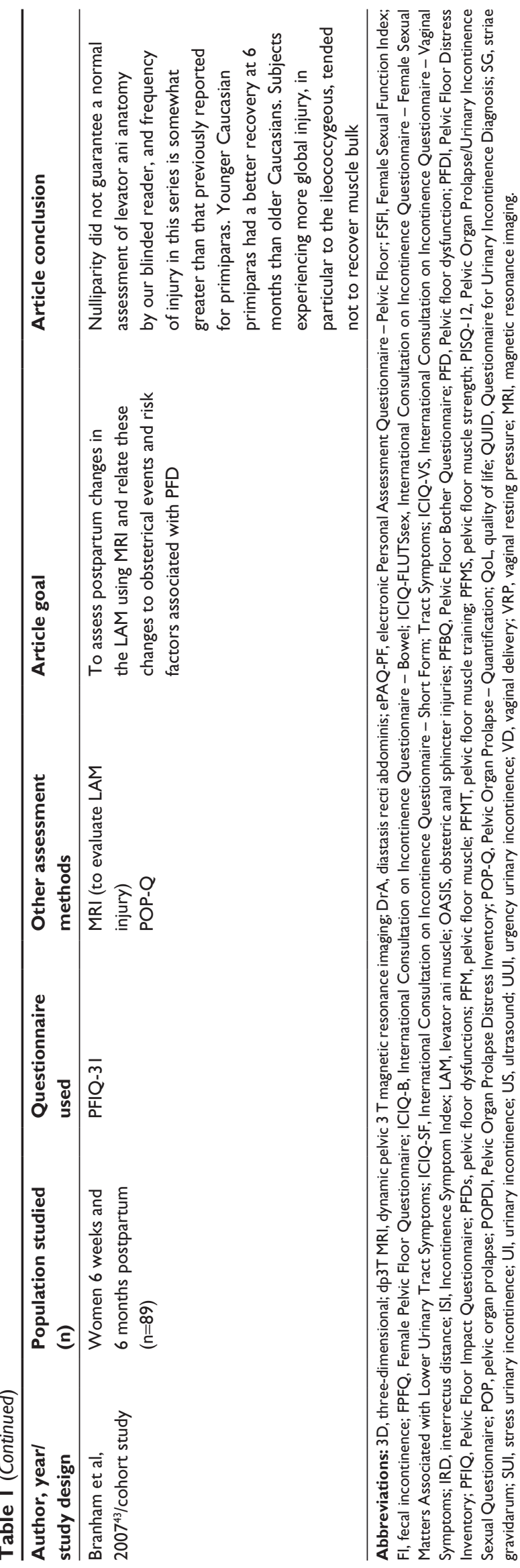

The other questionnaires (PFDI-46, PFIQ-31, ${ }^{72}$ Pelvic Floor Bother Questionnaire [PFBQ], ${ }^{75}$ electronic Personal Assessment Questionnaire - Pelvic Floor [ePAQ-PF], ${ }^{79}$ and PFD in pregnancy and postpartum ${ }^{16}$ ) were used in less than $10 \%$ of the studies.

\section{Discussion}

Systematic review of the literature found 33 published articles using nine validated questionnaires for assessing PFDs in the postpartum period: PFDI-20, PFIQ-7, PFDI-46, PFIQ-31, ICIQ-VS, FPFQ (or Australian PFQ), PFBQ, ePAQ-PF, and PFD questionnaire specific for pregnancy and postpartum.

The most frequent questionnaires in our revision were PFDI-20, PFIQ-7, and ICIQ-VS, and probably this is due to ICIQ-VS being part of modular questionnaires of the International Consultation on Incontinence (ICI) ${ }^{80}$ and PFDI-20 and PFIQ-7 were highly recommended (grade A) for the evaluation of symptoms and health-related $\mathrm{QoL}$ impact of POP by ICI. There is no questionnaire that is highly recommended to assess the PFD in a complete and integrated way by ICI.

The ICI is one of the consultations that are held under the auspices of the International Consultation on Urological Diseases and has a long-standing relationship with International Continence Society. The ICI aims to create an international consensus for evaluation of pelvic symptoms, recommending high-quality instruments, standardizing the evaluation of PFD and the impact on QoL, to guide professionals and researchers in the choice of instruments with universal application. ${ }^{80}$ The use of the same instrument for data collection by several researchers favors comparison between studies, allowing meta-analysis of the published results. ${ }^{9,80}$

Regarding the PFDI and PFIQ questionnaires, they were first created in longer versions with 46 and 31 questions, respectively, but because they were too long they became burdensome and time consuming, so the simplified version showed good correlation with the expanded versions, discouraging the use of PFDI-46 and PFIQ-31 versions. ${ }^{81}$

The PFDs include various symptoms, such as UI, FI, POP, sexual dysfunction, and vaginal symptoms, and could be investigated in an integrated model, because often the cause is the same. ${ }^{82}$

Voorham-van der Zalm et a ${ }^{83}$ said that PFDI-20, PFIQ-7, and ICIQ-VS are useful tools in research, but each one only assesses certain aspects of PFD and/or QoL. PFDI-20 and PFIQ-7 have some questions that address vaginal symptoms, but without emphasis on sexual factors, and ICIQ-VS is not able to assess bladder and bowel functions. The literature 
Table 2 Characterization, frequency, and translated and validated versions of questionnaires identified for evaluation of PFD in the postpartum period

\begin{tabular}{|c|c|c|c|c|c|}
\hline $\begin{array}{l}\text { Questionnaire/validation } \\
\text { article/country }\end{array}$ & $\begin{array}{l}\text { Domains - } \\
\text { questions }\end{array}$ & $\begin{array}{l}\text { Identified } \\
\text { categories }\end{array}$ & Translation & Freq (\%) & $\begin{array}{l}\text { Articles in which the } \\
\text { questionnaire was used }\end{array}$ \\
\hline PFDI-20/Barber et al, $2004^{44}$ & Urinary - 6 & Symptom & English, ${ }^{44, a}$ Spanish, ${ }^{45}$ & 10 & Lockhart et al, $2018^{12}$ \\
\hline \multirow[t]{9}{*}{ USA } & POP - 6 & Bother & Greek, ${ }^{46}$ Swedish, ${ }^{47}$ & $(30.3 \%)$ & Keshwani et al, $2018^{13}$ \\
\hline & Colorectal-anal - 8 & & Turkish, ${ }^{48}$ Brazilian & & Yohay et al, $2016^{21}$ \\
\hline & & & Portuguese,${ }^{49}$ & & Gagnon et al, $2016^{23}$ \\
\hline & & & Korean, ${ }^{50}$ French, ${ }^{51}$ & & Rikard-Bell et al, $2014^{31}$ \\
\hline & & & Danish, ${ }^{52}$ Norwegian, ${ }^{53}$ & & Adaji and Olajide, $2014^{34}$ \\
\hline & & & Japanese, ${ }^{54}$ Afrikaans, ${ }^{55}$ & & Geller et al, $2014^{36}$ \\
\hline & & & Sesotho, ${ }^{55}$ Dutch, ${ }^{56}$ & & Crane et al, $2013^{39}$ \\
\hline & & & Tigrigna, ${ }^{57}$ Hebrew, ${ }^{58}$ & & Tin et al, $2010^{41}$ \\
\hline & & & Finnish $^{59}$ & & Geller et al, $2007^{42}$ \\
\hline PFIQ-7/Barber et al, $2004^{44}$ & Urinary -7 & QoL & English, ${ }^{44, a}$ Spanish, ${ }^{45}$ & $9(27.3 \%)$ & Gagnon et al, $2016^{23}$ \\
\hline \multirow[t]{9}{*}{ USA } & POP - 7 & & Greek, ${ }^{46}$ Swedish, ${ }^{47}$ & & Cyr et al, $2016^{24}$ \\
\hline & Colorectal-anal - 7 & & Turkish, ${ }^{48}$ Brazilian & & Leeman et al, $2016^{25}$ \\
\hline & & & Portuguese,$^{49}$ & & Rogers et al, 2014 $4^{33}$ \\
\hline & & & Korean, ${ }^{50}$ French, ${ }^{51}$ & & Geller et al, $2014^{36}$ \\
\hline & & & Danish, ${ }^{52}$ Norwegian, ${ }^{53}$ & & Tin et al, $2010^{41}$ \\
\hline & & & Afrikaans, ${ }^{55}$ Sesotho, ${ }^{55}$ & & Geller et al, $2007^{42}$ \\
\hline & & & Dutch, ${ }^{56}$ Tigrigna, ${ }^{57}$ & & Lockhart et al, $2018^{12}$ \\
\hline & & & Hebrew, ${ }^{58}$ Finnish, ${ }^{59}$ & & Keshwani et al, $2018^{13}$ \\
\hline & & & Chinese $^{60}$ & & \\
\hline ICIQ-VS/Price et al, $2006^{61}$ & Vaginal - 9 & Symptom & English, ${ }^{61, a}$ German, ${ }^{62}$ & $8(24.2 \%)$ & Araujo et al, 2018"I \\
\hline \multirow[t]{7}{*}{ UK } & Sexual -5 & QoL & Portuguese, ${ }^{63}$ Greek, $^{64}$ & & Kruger et al, $2017^{15}$ \\
\hline & & Bother & Danish, ${ }^{65}$ Sinhala and & & Abdool et al, $2017^{17}$ \\
\hline & & & Tamil (Sri Lanka) ${ }^{66}$ & & $\begin{array}{l}\text { Kolberg Tennfjord } \\
\text { et al, } 2016^{22}\end{array}$ \\
\hline & & & & & Cyr et al, $2016^{24}$ \\
\hline & & & & & Tennfjord et al, $2015^{26}$ \\
\hline & & & & & van Delft et al, $2015^{27}$ \\
\hline & & & & & van Delft et al, 20I $4^{32}$ \\
\hline FPFQ/Baessler et al, 201067 & Bladder - 15 & Symptom & English, ${ }^{67,68, a}$ German, ${ }^{69}$ & $4(12.1 \%)$ & Durnea et al, $2017^{18}$ \\
\hline Baessler et al, $2009^{68}$ & Bowel - 12 & QoL & French, ${ }^{70}$ Serbian $^{71}$ & & Fritel et al, $2015^{28}$ \\
\hline \multirow[t]{2}{*}{ Australia } & POP - 5 & Bother & & & Laterza et al, $2015^{30}$ \\
\hline & Sexual -10 & & & & Durnea et al, $2014^{37}$ \\
\hline PFDI-46/Barber et al, 200I 72 & Urinary - 28 & Symptom & English, $^{72, a}$ Chinese, ${ }^{73}$ & $3(9.1 \%)$ & $\mathrm{Ng}$ et al, $2017^{19}$ \\
\hline \multirow[t]{2}{*}{ USA } & $P O P-16$ & Bother & Spanish $^{74}$ & & Chan et al, $2014^{35}$ \\
\hline & Colorectal-anal - $17^{\mathrm{b}}$ & & & & Chan et al, $2012^{40}$ \\
\hline PFIQ-3I/Barber et al, 200I72 & Urinary - 3I & QoL & English, ${ }^{72, a}$ Chinese, ${ }^{73}$ & $3(9.1 \%)$ & $\mathrm{Ng}$ et al, $2017^{19}$ \\
\hline \multirow[t]{2}{*}{ USA } & $P O P-31$ & & Spanish $^{74}$ & & Chan et al, $2014^{35}$ \\
\hline & Colorectal-anal - 3I & & & & Branham et al, $2007^{43}$ \\
\hline PFBQ/Peterson et al, 201075 & Urinary -5 & Bother & English, ${ }^{75, a}$ Turkish, ${ }^{76}$ & $3(9.1 \%)$ & Halperin et al, $2017^{14}$ \\
\hline \multirow[t]{3}{*}{ USA } & POP - I & & Arabic, ${ }^{77}$ Portuguese ${ }^{78}$ & & Desseauve et al, $2017^{20}$ \\
\hline & Bowel - 2 & & & & Lipschuetz et al, $2015^{29}$ \\
\hline & Sexual - I & & & & \\
\hline ePAQ-PF/Radley et al, $2005^{79}$ & Urinary -35 & Symptom & English $^{79, a}$ & $\mathrm{I}(3 \%)$ & Elenskaia et al, $2013^{38}$ \\
\hline \multirow[t]{3}{*}{ UK } & Bowel - 33 & QoL & & & \\
\hline & Vaginal - 22 & Bother & & & \\
\hline & Sexual -28 & & & & \\
\hline PFD in pregnancy and postpartum & Bladder - 16 & Symptom & German $^{16, a}$ & I (3\%) & Metz et al, $2017^{16}$ \\
\hline Metz et al, $2017^{16}$ & Bowel - II & QoL & & & \\
\hline \multirow[t]{3}{*}{ Germany } & POP - 5 & Bother & & & \\
\hline & Sexual -9 & & & & \\
\hline & Postpartum - 9 & & & & \\
\hline
\end{tabular}

Notes: ${ }^{a}$ Original version of the questionnaire. ${ }^{b}$ In the PFDI-46 questionnaire, some questions are used in more than one domain.

Abbreviations: ePAQ-PF, electronic Personal Assessment Questionnaire - Pelvic Floor; FPFQ, Female Pelvic Floor Questionnaire; ICIQ-VS, International Consultation on Incontinence Questionnaire - Vaginal Symptoms; PFBQ, Pelvic Floor Bother Questionnaire; PFDI, Pelvic Floor Distress Inventory; PFIQ, Pelvic Floor Impact Questionnaire; POP, pelvic organ prolapse; QoL, quality of life. 
provides several standardized questionnaires, but each one assesses certain domains of PFD, and they are specific to evaluate symptoms, QoL, and/or bothersome. ${ }^{80,82,83}$

Among the questionnaires included in this review, ePAQ-PF, FPFQ, and PFBQ can evaluate all these domains, but there are some limiting factors for wide use in literature.

The ePAQ-PF ${ }^{79}$ is an interactive, self-administered, computer-based questionnaire, developed for clinical practice and validated in primary and secondary care assessing four dimensions (urinary, intestinal, vaginal, and sexual) with symptoms identification, as well as quantifying degree of bother and impact on QoL. Indeed, the ePAQ-PF is not used extensively for reasons that include cost implications involved in purchasing an ePAQ license, and has no translated versions, limiting widespread use in researches. ${ }^{84}$

The $\mathrm{PFBQ}^{75}$ questionnaire was validated in 2010 with the proposal to create a concise questionnaire that could verify the presence and degree of discomfort of the PFD, allowing its use in both clinical practice and research. But the questions were not well distributed among the domains, because it contains only nine questions, with an emphasis on urinary symptoms (five questions) and only one question for POPs and one question for sexual functions. Another limiting factor is the existence of translated versions in only four languages (English, Turkish, Arabic, and Portuguese), with the Portuguese version just being published.

The FPFQ is a complete questionnaire that can assess all domains, besides addressing the perception of symptoms, the impact on QoL, and the degree of bother, validated in community-dwelling women for application by interview ${ }^{67}$ and for self-application. ${ }^{68}$ Both versions are composed of 42 questions distributed in four domains: bladder function (15 questions), bowel function (12 questions), POP symptoms (five questions), and sexual function (10 questions).

However, its use is still scarce, as it was introduced only recently in the scientific literature, originally developed and validated in the English language, with versions translated and adapted for application in German, ${ }^{69}$ French, ${ }^{70}$ and Serbian. ${ }^{71}$

The ICI recommendation also encourages researchers to the translation and validation of these instruments in different languages. The existence of translated and validated versions in several languages also corroborates the widespread use of these evaluation tools in research conducted around the world. ${ }^{80,85}$ This method makes it possible to compare results across studies, despite different languages and cultures because the data come from the same instrument. It also allows the study to be carried out on a larger scale with international participation.

None of these questionnaires described till now were developed to be specifically applied to postpartum women, and most questionnaires have been developed for use with general population or urology/gynecology patients with incontinence.

The PFD has been described during late reproductive period and the occurrence of worsening of symptoms among nonreproductive life. Risk factors such as overweight, obesity, life habits (smoking, sedentarism), age, parity, and mode of delivery have been shown as a health-related multifactorial risk that can be modified and interfered by the health care professionals. ${ }^{82,86}$ Indeed, the postpartum period is favorable and has been studied as an important period to early detection and early intervention.

Despite the generally high prevalence of postpartum PFD, the pelvic floor function is not routinely evaluated in health system. ${ }^{1,2,87}$ Therefore, the evaluation of an instrument capable of identifying the presence of these symptoms is useful for health promotion and prevention of comorbidities. Health instruments, such as PFD questionnaires, are developed to quantify the often-qualitative symptoms that are underreported and normally coexist and affect the QoL and productivity of many women. ${ }^{88}$ The questionnaires are used to identify and amplify early diagnosis and to assist the professionals in monitoring these symptoms, even when they are poorly perceived or not explained by the patients. ${ }^{89}$

Uniformity in obtaining symptoms and clinical complaints by professionals directs and enables evidence-based decision, allowing specialized societies to conduct behaviors and guide the management for PFD. It should be stressed that the health instruments established and recommended by societies, as well as the guidelines are fundamental in developing countries and in countries that adopt primary health care as the main access of patients. ${ }^{89}$

Furthermore, postpartum evaluation requires validated and preferred questionnaires that were designed for women during this period of life. Luthander et $\mathrm{al}^{90}$ believe that the greatest symptoms of PFD are related to the need of reviewing obstetric care. Thus, it serves as a tool for evaluating obstetric practices, allowing the identification of possible failures and the improvement in obstetric care.

Recently, Metz et $\mathrm{al}^{16}$ (2017) developed a questionnaire to assess PFDs in pregnancy and postpartum, and it is based on the German version of the FPFQ, with some modifications to access younger women. However, because this questionnaire is a recent addition to the field and only in German version, 
its usefulness has not yet been thoroughly analyzed in clinical practice and further research is necessary to evaluate its feasibility and accessibility.

Still, the ICI advises that researchers should use existing highly recommended or recommended questionnaires if possible as this aids comparison, and to reduce the increasing proliferation of questionnaires. ${ }^{80,85}$

This review assists health care professionals and researchers in choosing an assessment tool for postpartum PFDs and proposes standardization in the method of research and scientific work. For the choice of questionnaire, it is suggested to use those validated and recommended by the academic society for population surveys and clinical practice of primary health care. ${ }^{80,85}$

The assessment of postpartum PDF is necessary to identify these symptoms, avoiding the evolution of these disorders. The international literature reveals that PFD tools developed specifically for women in postpartum period still need to be better explored and developed, allowing early treatment and comprehensive approach by the gynecologist and health care providers. ${ }^{16,90}$ There is still no questionnaire that is highly recommended for this purpose by ICI. ${ }^{80,85}$ They encourage researchers to raise the standard of outcome assessment and trial methodology in these fields in the forthcoming years.

\section{Limitations}

One of the limitations of this systematic review was the choice of appropriate keywords for the evaluation of PFDs. The term used in the literature is Pelvic Floor Dysfunction, but it is registered in the MeSH as Pelvic Floor Disorders. The two descriptors were used according to the citations in the literature. In addition, different types of reporting biases may hinder the interpretation of systematic reviews. Other limitation was the exclusion of articles published in journals with restricted access being 14 titles excluded. Besides that, the research was focused on articles published in peer-reviewed journals, excluding reports and books.

\section{Conclusion}

The most frequently reported questionnaires in this review included PFDI-20, PFIQ-7, and ICIQ-VS and are recommended by ICI. In addition, the review identified a specific questionnaire, recently developed, to access PFD during pregnancy and postpartum. ${ }^{16}$

This review reveals that the questionnaires used to evaluate PFD during postpartum period are developed for the general population or urology/gynecology patients with incontinence and reinforce the paucity of highly recommended questionnaires designed for postpartum, in order to improve early and specific approach for this period of life.

\section{Disclosure}

The authors report no conflicts of interest in this work.

\section{References}

1. Nygaard I. Prevalence of symptomatic pelvic floor disorders in US women. JAMA. 2008;300(11):1311-1316.

2. Dieter AA, Wilkins MF, Wu JM. Epidemiological trends and future care needs for pelvic floor disorders. Curr Opin Obstet Gynecol. 2015;27(5):380-384.

3. Walker GJA, Gunasekera P. Pelvic organ prolapse and incontinence in developing countries: review of prevalence and risk factors. Int Urogynecol J. 2011;22(2):127-135.

4. Wu JM, Hundley AF, Fulton RG, Myers ER. Forecasting the prevalence of pelvic floor disorders in U.S. Women: 2010 to 2050. Obstet Gynecol. 2009;114(6):1278-1283.

5. Groutz A, Rimon E, Peled S, et al. Cesarean section: Does it really prevent the development of postpartum stress urinary incontinence? a prospective study of 363 women one year after their first delivery. Neurourol Urodyn. 2004;23(1):2-6.

6. Swift S, Woodman P, O'Boyle A, O’Boyle A, et al. Pelvic Organ Support Study (POSST): the distribution, clinical definition, and epidemiologic condition of pelvic organ support defects. Am J Obstet Gynecol. 2005;192(3):795-806.

7. Aguilar VC, White AB, Rogers RG. Updates on the diagnostic tools for evaluation of pelvic floor disorders. Curr Opin Obstet Gynecol. 2017;29(6): $1-464$.

8. Cella D, Yount S, Rothrock N, et al. The Patient-Reported Outcomes Measurement Information System (PROMIS). Med Care. 2007;45(Suppl 1): S3-S11.

9. Barber MD. Questionnaires for women with pelvic floor disorders. Int Urogynecol J. 2007;18(4):461-465.

10. Moher D, Liberati A, Tetzlaff J, Altman DG; The PRISMA Group. Preferred reporting items for systematic reviews and meta-analyses: the PRISMA statement. PLoS Med. 2009;6(7):e1000097.

11. Araujo CC, Coelho SS, Martinho N, Tanaka M, Jales RM, Juliato CR. Clinical and ultrasonographic evaluation of the pelvic floor in primiparous women: a cross-sectional study. Int Urogynecol J. 2018:1-7.

12. Lockhart ME, Bates GW, Morgan DE, Beasley TM, Richter HE. Dynamic $3 \mathrm{~T}$ pelvic floor magnetic resonance imaging in women progressing from the nulligravid to the primiparous state. Int Urogynecol $J$. 2018;29(5):735-744.

13. Keshwani N, Mathur S, Mclean L. Relationship between interrectus distance and symptom severity in women with diastasis recti abdominis in the early postpartum period. Phys Ther. 2018;98(3):182-190.

14. Halperin O, Noble A, Balachsan S, Klug E, Liebergall-Wischnitzer M. Association between severities of striae gravidarum and Obstetric Anal Sphincter Injuries (OASIS). Midwifery. 2017;54:25-28.

15. Kruger JA, Budgett SC, Wong V, et al. Characterizing levator-ani muscle stiffness pre- and post-childbirth in European and Polynesian women in New Zealand: a pilot study. Acta Obstet Gynecol Scand. 2017;96(10):1234-1242.

16. Metz M, Junginger B, Henrich W, Baeßler K. Development and validation of a questionnaire for the assessment of pelvic floor disorders and their risk factors during pregnancy and post partum. Geburtshilfe Frauenheilkd. 2017;77(4):358-365.

17. Abdool Z, Lindeque BG, Dietz HP. The impact of childbirth on pelvic floor morphology in primiparous Black South African women: a prospective longitudinal observational study. Int Urogynecol J. 2017;29(3): 369-375. 
18. Durnea CM, Khashan AS, Kenny LC, et al. What is to blame for postnatal pelvic floor dysfunction in primiparous women-Pre-pregnancy or intrapartum risk factors? Eur J Obstet Gynecol Reprod Biol. 2017;214: 36-43.

19. Ng K, Cheung RYK, Lee LL, Chung TKH, Chan SSC. An observational follow-up study on pelvic floor disorders to 3-5 years after delivery. Int Urogynecol J. 2017;28(9):1393-1399.

20. Desseauve D, Proust S, Carlier-Guerin C, Rutten C, Pierre F, Fritel X. Evaluation of long-term pelvic floor symptoms after an obstetric anal sphincter injury (OASI) at least one year after delivery: a retrospective cohort study of 159 cases. Gynécologie Obstétrique \& Fertilité. 2016; 44(7-8):385-390.

21. Yohay D, Weintraub AY, Mauer-Perry N, et al. Prevalence and trends of pelvic floor disorders in late pregnancy and after delivery in a cohort of Israeli women using the PFDI-20. Eur J Obstet Gynecol Reprod Biol. 2016;200:35-39.

22. Kolberg Tennfjord M, Hilde G, Staer-Jensen J, Siafarikas F, Engh ME, $\mathrm{B} ø \mathrm{~K}$. Effect of postpartum pelvic floor muscle training on vaginal symptoms and sexual dysfunction-secondary analysis of a randomised trial. BJOG. 2016;123(4):634-642.

23. Gagnon LH, Boucher J, Robert M. Impact of pelvic floor muscle training in the postpartum period. Int Urogynecol J. 2016;27(2): 255-260.

24. Cyr M-P, Kruger J, Wong V, Dumoulin C, Girard I, Morin M. Pelvic floor morphometry and function in women with and without puborectalis avulsion in the early postpartum period. Am J Obstet Gynecol. 2016; 216(3):274.e1274.e8.

25. Leeman L, Rogers R, Borders N, Teaf D, Qualls C. The effect of perineal lacerations on pelvic floor function and anatomy at 6 months postpartum in a prospective cohort of nulliparous women. Birth. 2016; 43(4):293-302.

26. Tennfjord MK, Hilde G, Stær-Jensen J, Siafarikas F, Engh ME, Bø K. Coital incontinence and vaginal symptoms and the relationship to pelvic floor muscle function in primiparous women at 12 months postpartum: a cross-sectional study. J Sex Med. 2015;1212(4):994-1003.

27. van Delft KW, Thakar R, Sultan AH, Inthout J, Kluivers KB. The natural history of levator avulsion one year following childbirth: a prospective study. BJOG. 2015;122(9):1266-1273.

28. Fritel X, de Tayrac R, Bader G, et al. Preventing urinary incontinence with supervised prenatal pelvic floor exercises: a randomized controlled trial. Obs Gynecol. 2015;126(2):370-377.

29. Lipschuetz M, Cohen SM, Liebergall-Wischnitzer M, et al. Degree of bother from pelvic floor dysfunction in women one year after first delivery. Eur J Obstet Gynecol Reprod Biol. 2015;191:90-94.

30. Laterza RM, Schrutka L, Umek W, Albrich S, Koelbl H. Pelvic floor dysfunction after levator trauma 1-year postpartum: a prospective casecontrol study. Int Urogynecol J. 2015;26(1):41-47.

31. Rikard-Bell J, Iyer J, Rane A. Perineal outcome and the risk of pelvic floor dysfunction: a cohort study of primiparous women. Aust $N Z \mathrm{~J}$ Obstet Gynaecol. 2014;54(4):371-376.

32. van Delft K, Sultan AH, Thakar R, Schwertner-Tiepelmann N, Kluivers K. The relationship between postpartum levator ani muscle avulsion and signs and symptoms of pelvic floor dysfunction. BJOG. 2014;121(9): 1164-1172.

33. Rogers RG, Leeman LM, Borders N, et al. Contribution of the second stage of labour to pelvic floor dysfunction: a prospective cohort comparison of nulliparous women. BJOG. 2014;121(9):1145-1154.

34. Adaji SE, Olajide FM. Pelvic floor distress symptoms within 9 weeks of childbirth among Nigerian women. Eur J Obstet Gynecol Reprod Biol. 2014;174(1):54-58.

35. Chan SSC, Cheung RYK, Yiu KW, Lee LL, Chung TKH. Effect of levator ani muscle injury on primiparous women during the first year after childbirth. Int Urogynecol J. 2014;25(10):1381-1388.

36. Geller EJ, Robinson BL, Matthews CA, et al. Perineal body length as a risk factor for ultrasound-diagnosed anal sphincter tear at first delivery. Int Urogynecol J. 2014;25(5):631-636.
37. Durnea CM, Khashan AS, Kenny LC, Tabirca SS, O’Reilly BA. The role of prepregnancy pelvic floor dysfunction in postnatal pelvic morbidity in primiparous women. Int Urogynecol J. 2014;25(10): 1363-1374

38. Elenskaia K, Thakar R, Sultan AH, Scheer I, Onwude J. Effect of childbirth on pelvic organ support and quality of life: a longitudinal cohort study. Int Urogynecol J. 2013;24(6):927-937.

39. Crane AK, Geller EJ, Bane H, Ju R, Myers E, Matthews CA. Evaluation of pelvic floor symptoms and sexual function in primiparous women who underwent operative vaginal delivery versus cesarean delivery for second-stage arrest. Female Pelvic Med Reconstr Surg. 2013; 19(1):13-16.

40. Chan SSC, Cheung RYK, Yiu KW, Lee LL, Chung TKH. Prevalence of urinary and fecal incontinence in Chinese women during and after their first pregnancy. Int Urogynecol J. 2012;24(9):1473-1479.

41. Tin RY, Schulz J, Gunn B, Flood C, Rosychuk RJ. The prevalence of anal incontinence in post-partum women following obstetrical anal sphincter injury. Int Urogynecol J. 2010;21(8):927-932.

42. Geller EJ, Barbee ER, Wu JM, Loomis MJ, Visco AG. Validation of telephone administration of 2 condition-specific quality-of-life questionnaires. Am J Obstet Gynecol. 2007;197(6):632.e1-e4.

43. Branham VG, Thomas J, Jaffe TA, et al. Levator ani abnormality six weeks after delivery persists at six months. Am J Obs Gynecol. 2007;197(1):65.e1-e6.

44. Barber MD, Walters MD, Bump RC. Short forms of two condition-specific quality-of-life questionnaires for women with pelvic floor disorders (PFDI-20 and PFIQ-7). Am J Obstet Gynecol. 2005;193(1): 103-113.

45. Treszezamsky AD, Karp D, Dick-Biascoechea M, et al. Spanish translation and validation of four short pelvic floor disorders questionnaires. Int Urogynecol J. 2013;24(4):655-670.

46. Grigoriadis T, Athanasiou S, Giannoulis G, Mylona S-C, Lourantou D, Antsaklis A. Translation and psychometric evaluation of the Greek short forms of two condition-specific quality of life questionnaires for women with pelvic floor disorders: PFDI-20 and PFIQ-7. Int Urogynecol J. 2013;24(12):2131-2144.

47. Teleman PIA, Stenzelius K, Iorizzo L, Jakobsson ULF. Validation of the Swedish short forms of the Pelvic Floor Impact Questionnaire (PFIQ-7), Pelvic Floor Distress Inventory (PFDI-20) and Pelvic Organ Prolapse/ Urinary Incontinence Sexual Questionnaire (PISQ-12). Acta Obstet Gynecol Scand. 2011;90(5):483-487.

48. Kaplan PB, Sut N, Sut HK. Validation, cultural adaptation and responsiveness of two pelvic-floor-specific quality-of-life questionnaires, PFDI-20 and PFIQ-7, in a Turkish population. Eur J Obstet Gynecol Reprod Biol. 2012;162(2):229-233.

49. Arouca MAF, Duarte TB, Lott DAM, et al. Validation and cultural translation for Brazilian Portuguese version of the Pelvic Floor Impact Questionnaire (PFIQ-7) and Pelvic Floor Distress Inventory (PFDI-20). Int Urogynecol J. 2016;27(7):1097-1106.

50. Yoo E-H, Jeon MJ, Ahn K-H, Bai SW. Translation and linguistic validation of Korean version of short form of pelvic floor distress inventory-20, pelvic floor impact questionnaire-7. Obstet Gynecol Sci. 2013;56(5):330-332.

51. de Tayrac R, Deval B, Fernandez H, Marès P; Mapi Research Institute. Development of a linguistically validated French version of two shortform, condition-specific quality of life questionnaires for women with pelvic floor disorders (PFDI-20) and (PFIQ-7). J Gynecol Obstet Biol Reprod. 2007;36(8):738-748.

52. Due U, Brostrøm S, Lose G. Validation of the Pelvic Floor Distress Inventory-20 and the Pelvic Floor Impact Questionnaire-7 in Danish women with pelvic organ prolapse. Acta Obstet Gynecol Scand. 2013;92(9): 1041-1048.

53. Teig CJ, Grotle M, Bond MJ, et al. Norwegian translation, and validation, of the Pelvic Floor Distress Inventory (PFDI-20) and the Pelvic Floor Impact Questionnaire (PFIQ-7). Int Urogynecol J. 2017;28(7): 1005-1017. 
54. Yoshida M, Murayama R, Ota E, Nakata M, Kozuma S, Homma Y. Reliability and validity of the Japanese version of the pelvic floor distress inventory-short form 20. Int Urogynecol J. 2013;24(6): 1039-1046.

55. Henn EW, Richter BW, Marokane MMP. Validation of the PFDI-20 and PFIQ-7 quality of life questionnaires in two African languages. Int Urogynecol J. 2017;28(12):1883-1890.

56. Utomo E, Blok BF, Steensma AB, Korfage IJ. Validation of the Pelvic Floor Distress Inventory (PFDI-20) and Pelvic Floor Impact Questionnaire (PFIQ-7) in a Dutch population. Int Urogynecol J. 2014;25(4):531-544

57. Goba GK, Legesse AY, Zelelow YB, et al. Reliability and validity of the Tigrigna version of the Pelvic Floor Distress Inventory-Short Form 20 (PFDI-20) and Pelvic Floor Impact Questionnaire-7 (PFIQ-7). Int Urogynecol J. 2018:1-6.

58. Lowenstein L, Levy G, Chen KO, Ginath S, Condrea A, Padoa A. Validation of hebrew versions of the pelvic floor distress inventory, pelvic organ prolapse/urinary incontinence sexual function questionnaire, and the urgency, severity and impact questionnaire. Female Pelvic Med Reconstr Surg. 2012;18(6):329-331.

59. Mattsson NK, Nieminen K, Heikkinen AM, et al. Validation of the short forms of the Pelvic Floor Distress Inventory (PFDI-20), Pelvic Floor Impact Questionnaire (PFIQ-7), and Pelvic Organ Prolapse/Urinary Incontinence Sexual Questionnaire (PISQ-12) in Finnish. Health Qual Life Outcomes. 2017;15(1):88.

60. Zhu L, Yu S, Xu T, et al. Chinese validation of the pelvic floor impact questionnaire short form. Menopause. 2011;18(9):1030-1033.

61. Price N, Jackson SR, Avery K, Brookes ST, Abrams P. Development and psychometric evaluation of the ICIQ Vaginal Symptoms Questionnaire: the ICIQ-VS. BJOG. 2006;113(6):700-712.

62. Banerjee C, Banerjee M, Hatzmann W, et al. The German Version of the 'ICIQ Vaginal Symptoms Questionnaire' (German ICIQ-VS): An Instrument Validation Study. Urol Int. 2010;85(1):70-79.

63. Tamanini JTN, Almeida FG, Girotti ME, Riccetto CLZ, Palma PCR, Rios LAS. The Portuguese validation of the International Consultation on Incontinence Questionnaire - Vaginal Symptoms (ICIQ-VS) for Brazilian women with pelvic organ prolapse. Int Urogynecol J. 2008;19(10): 1385-1391.

64. Stavros A, Themistoklis G, Niki K, George G, Aristidis A. The validation of international consultation on incontinence questionnaires in the Greek language. Neurourol Urodyn. 2012;31(7):1141-1144.

65. Arenholt LTS, Glavind-Kristensen M, Bøggild H, Glavind K. Translation and validation of the International Consultation on Incontinence Questionnaire Vaginal Symptoms (ICIQ-VS): the Danish version. Int Urogynecol J. 2018:1-6.

66. Ekanayake CD, Pathmeswaran A, Herath RP, Perera HSS, Patabendige M, Wijesinghe PS. Validation of the International Consultation on Incontinence Questionnaire-Vaginal Symptoms (ICIQ-VS) in two south-Asian languages. Int Urogynecol J. 2017;28(12):1849-1855.

67. Baessler K, O’Neill SM, Maher CF, Battistutta D. A validated selfadministered female pelvic floor questionnaire. Int Urogynecol J. 2010;21(2):163-172.

68. Baessler K, O’Neill SM, Maher CF, Battistutta D. Australian pelvic floor questionnaire: a validated interviewer-administered pelvic floor questionnaire for routine clinic and research. Int Urogynecol J. 2009;20(2):149-158.

69. Baessler K, Kempkensteffen C. Validierung eines umfassenden Beckenboden-Fragebogens für Klinik, Praxis und Forschung Gynäkologisch-geburtshilfliche Rundschau. 2009;49(4):299-307.

70. Deparis J, Bonniaud V, Desseauve D, et al. Cultural adaptation of the female pelvic floor questionnaire (FPFQ) into French. Neurourol Urodyn. 2017;36(2):253-258.

71. Argirović A, Tulić C, Kadija S, Soldatović I, Babić U, Nale D. Crosscultural adaptation and validation of the Serbian version of the Australian pelvic floor questionnaire. Int Urogynecol J. 2015;26(1):131-138.
72. Barber MD, Kuchibhatla MN, Pieper CF, Bump RC. Psychometric evaluation of 2 comprehensive condition-specific quality of life instruments for women with pelvic floor disorders. Am J Obstet Gynecol. 2001; 185(6):1388-1395.

73. Chan SSC, Cheung RYK, Yiu AKW, Akw Y, et al. Chinese validation of Pelvic Floor Distress Inventory and Pelvic Floor Impact Questionnaire. Int Urogynecol J. 2011;22(10):1305-1312.

74. Omotosho TB, Hardart A, Rogers RG, Schaffer JI, Kobak WH, Romero AA. Validation of Spanish versions of the Pelvic Floor Distress Inventory (PFDI) and Pelvic Floor Impact Questionnaire (PFIQ): a multicenter validation randomized study. Int Urogynecol J. 2009;20(6):623-639.

75. Peterson TV, Karp DR, Aguilar VC, Davila GW. Validation of a global pelvic floor symptom bother questionnaire. Int Urogynecol J. 2010;21(9): 1129-1135.

76. Doğan H, Özengin N, Bakar Y, Duran B. Reliability and validity of a Turkish version of the Global Pelvic Floor Bother Questionnaire. Int Urogynecol J. 2016;27(10):1577-1581.

77. Bazi T, Kabakian-Khasholian T, Ezzeddine D, Ayoub H. Validation of an Arabic version of the global Pelvic Floor Bother Questionnaire. Int J Gynaecol Obstet. 2013;121(2):166-169.

78. Peterson TV, Pinto RA, Davila GW, Nahas SC, Baracat EC, Haddad JM. Validation of the Brazilian Portuguese version of the pelvic floor bother questionnaire. Int Urogynecol J. 2018:1-8.

79. Radley SC, Jones GL, Tanguy EA, Stevens VG, Nelson C, Mathers NJ. Computer interviewing in urogynaecology: concept, development and psychometric testing of an electronic pelvic floor assessment questionnaire in primary and secondary care. BJOG. 2006;113(2):231-238.

80. Abrams P, Cardozo L, Khoury S, Wein A. Incontinence. Vol. 5th ed. Paris: Plymouth: Health Publication; 2013:428.

81. Barber MD, Chen Z, Lukacz E, et al. Further validation of the short form versions of the pelvic floor Distress Inventory (PFDI) and pelvic floor impact questionnaire (PFIQ). Neurourol Urodyn. 2011;30(4): 541-546.

82. Wall LL, Delancey JOL. The politics of prolapse: a revisionist approach to disorders of the pelvic floor in women. Perspect Biol Med. 1991;34(4):486-496.

83. Voorham-van der Zalm PJ, Berzuk K, Shelly B, et al. Validation of the pelvic floor inventories Leiden (PelFIs) in English. Neurourol Urodyn. 2011;30(4):536-540.

84. Mccooty S, Latthe P. Electronic pelvic floor assessment questionnaire: a systematic review. Br J Nurs. 2014;23(Sup18):S32-S37.

85. Avery KNL, Bosch JLHR, Gotoh M, et al. Questionnaires to assess urinary and anal incontinence: review and recommendations. J Urol. 2007;177(1):39-49.

86. Galhardo CL, Soares JM Jr, Simões RS, Haidar MA, Rodrigues de Lima G, Baracat EC. Estrogen effects on the vaginal $\mathrm{pH}$, flora and cytology in late postmenopause after a long period without hormone therapy. Clin Exp Obstet Gynecol. 2006;33(2):85-89.

87. da Silva ATM, Menezes CL, de Sousa Santos EF, et al. Referral gynecological ambulatory clinic: principal diagnosis and distribution in health services. BMC Womens Health. 2018;18(1):8.

88. Bezerra IMP, Sorpreso ICE. Concepts and movements in health promotion to guide educational practices. Journal of Human Growth and Development. 2016;26(1):11-20.

89. Buurman MBR, Lagro-Janssen ALM. Women's perception of postpartum pelvic floor dysfunction and their help-seeking behaviour: a qualitative interview study. Scand J Caring Sci. 2013;27(2): 406-413.

90. Luthander C, Emilsson T, Ljunggren G, Hammarström M. A questionnaire on pelvic floor dysfunction postpartum. Int Urogynecol J. 2011;22(1):105-113. 
International Journal of Women's Health

\section{Dovepress}

\section{Publish your work in this journal}

The International Journal of Women's Health is an international, peerreviewed open-access journal publishing original research, reports, editorials, reviews and commentaries on all aspects of women's healthcare including gynecology, obstetrics, and breast cancer. The Visit http://www.dovepress.com/testimonials.php to read real quotes from published authors.

manuscript management system is completely online and includes

Submit your manuscript here: http://www.dovepress.com/international-journal-of-womens-health-journal 